\title{
FORMAÇÃO BINACIONAL DE PROFESSORES: O CASO DA FRONTEIRA DO ARIZONA ${ }^{1}$
}

\author{
ETTA KRALOVEC \\ Professora da Universidade do Arizona (EUA) \\ kravolec@email.arizona.edu
}

O termo "fronteira" tem adquirido um significado cada vez mais amplo no século XXI como corolário político e econômico do capitalismo global e à medida que a ascensão do nacionalismo cobra seu preço na vida cotidiana dos espaços fronteiriços (Paasi, 2011). Ainda que o termo fronteira possa ser usado para se referir à fronteira literária ou "La Frontera"; e ao "espaço liminar" ocupado pelos fronteiriços (Anzaldúa, 2011; Elenes, 2011); neste capítulo, uso o termo para me referir especificamente à fronteira física entre os Estados Unidos (no estado do Arizona) e o México (no estado de Sonora) e às escolas a ela adjacentes.

O foco deste capítulo recai sobre questões educacionais ao longo dessa fronteira, baseando-se sobretudo em minhas próprias experiências com escolas no Arizona e em Sonora. Para o aprendizado, pode ser fundamental o conceito de "fundos de conhecimento", que reconhece que as práticas culturais e o corpo de conhecimentos estão incorporados no cotidiano das famílias e que cada criança os traz consigo para a escola (Gonzalez; Moll; Amanti, 2005). A análise da experiência do aluno latino, desenvolvida a partir do esquema conceitual dos fundos de conhecimento, molda a maneira como compreendemos as experiências escolares (Valdes, 1996; Rippberger; Staudt, 2003; López, 2017). Além disso, este trabalho é informado pelo aparato conceitual que explora a intersecção da educação escolar com o desenvolvimento da identidade dos alunos (Verhoeven; Poorthuis; Volman, 2019).

1 Tradução de Walkiria Ayres Sidi (tradutora e doutora em Letras pela UFRGS) e de Paulo Bunselmeyer Ferreira (Licenciado em Letras pela UFRGS). Revisão de Adriana Dorfman (Dra. em Geografia e Professora do Depto. de Geografia da UFRGS). 


\section{Contexto}

Venho preparando professores para atuar nas escolas da fronteira do Arizona / Sonora há mais de uma década. Vim para a região a fim de observar os desafios por eles enfrentados nessas escolas, em que muitos estudantes atravessam a fronteira todos os dias para frequentá-las. Outros realizam parte dos estudos no México e parte nas escolas do Arizona. E tantos outros passam feriados e fins de semana prolongados com suas famílias no México e semestres escolares nos EUA, onde a vida no México é praticamente excluída.

Nosso trabalho situa-se em municípios rurais que compartilham uma fronteira com o estado de Sonora, no México, onde $26 \%$ do público escolar com idade inferior a 18 anos vive na pobreza. A maioria dos docentes das escolas de fronteira no Arizona é anglo-americana, enquanto a maioria dos estudantes é latina. Algumas das escolas trabalhadas enfrentam dificuldades para encontrar professores e, atualmente, precisam agenciá-los na Índia e nas Filipinas. Essa solução cada vez mais popular para a falta de profissionais da educação em escolas urbanas e rurais nos EUA é facilitada pelas empresas de recrutamento, que encontram vagas para professores estrangeiros com vistos de trabalho temporário de três anos, cobrando comissões tanto dos docentes visitantes quanto do distrito escolar onde eles são alocados (Dunn, 2013). Os professores estrangeiros são anunciados como "embaixadores culturais", mas a realidade é que os estudantes geralmente precisam se esforçar para compreender muitos desses docentes, o que causa grandes problemas de comunicação na sala de aula (Dunn, 2013, p. 33). Em algumas das escolas de fronteira, eles precisam viajar cerca de 70 milhas ou mais de 100 quilômetros para desempenhar suas funções. Como resultado, demonstram pouca conexão e compreensão da vida comunitária na fronteira.

Nos últimos 15 anos, a vida na fronteira entre Arizona e Sonora ficou mais complicada devido ao impacto dos ataques de 11 de setembro, que justificam toda sorte de medidas de segurança nacional, a avassaladora legislação anti-imigração, à ascensão do nacionalismo e à eleição de um presidente americano que fez da política rígida de combate à imigração a sua marca registrada. Antes desse período, várias iniciativas promissoras de trabalho em espaços fronteiriços em benefício do alunado estavam em andamento. Após 11 de setembro, as novas restrições à transposição 
da fronteira significaram a interrupção de grande parte do trabalho que estava sendo iniciado no Texas, Califórnia e Arizona. Por exemplo, após o 11 de setembro, uma instituição de ensino comunitária na fronteira do Arizona perdeu quase $20 \%$ de seu alunado devido ao aumento de regulamentações para vistos estudantis e ao crescente sentimento anti-imigrantista nos EUA (Orozco, 2008). No Arizona, a repressiva legislação anti-imigração começou efetivamente em 2000, quando os eleitores impuseram severas restrições à educação bilíngue e aprovaram, em 2002, a Proposição 200, que restringia o uso de serviços sociais por imigrantes sem comprovação de cidadania. Em 2004, a Proposição 300 restringiu o auxílio financeiro ao ensino institucional a qualquer pessoa que não fosse cidadão americano. Em 2007, a legislação do Arizona impôs pesadas sanções aos empregadores que contratassem trabalhadores sem documentos. O Projeto de Lei 1070 do Senado, aprovado em 2010, deu à polícia o poder de exigir documentos de imigração e de aplicar outras leis. Essas reformas na lei eram parte de um esforço nacional liderado pela Federação para a Reforma da Imigração Americana (FAIR - Federation for American Immigration Reform, na sigla em inglês) para restringir os direitos de imigrantes em todo o país. Essas leis tiveram um efeito intimidante sobre as cerca de 460.000 pessoas sem documentação no Arizona. Além disso, o Superintendente Estadual de Instrução proibiu os cursos de Estudos Étnicos, de grande sucesso nas escolas de ensino médio em Tucson, e promulgou legislação que os tornava ilegais no Arizona. O estado alegou que esses cursos estavam ensinando comunismo e sedição. Após uma batalha judicial de sete anos, um juiz federal concluiu que a lei: “(...) não foi promulgada e implementada com um propósito educacional legítimo, mas com um propósito racial discriminatório e injusto, e com objetivo politicamente partidário (...) [a lei] não pode ser aplicada" (Associated Press, 2017).

Além desse histórico de ataques legais aos imigrantes, o governo Trump transformou a fronteira em uma zona militarizada, erguendo mais muros, aumentando a vigilância e construindo centros de detenção improvisados que abrigam famílias que buscavam asilo nos EUA. A crise na fronteira continua a crescer, com um acúmulo de 1 milhão de pedidos de asilo que aguardam processamento e com muitos dos solicitantes alojados em centros de detenção aguardando suas audiências. Recentemente, juízes federais declararam que esses centros de de- 
tenção privam os migrantes de "necessidades humanas básicas" (Flynn, 2020). O governo Trump começou a usar as Forças de Operações Especiais do exército nas “cidades santuário” (municípios que limitam sua cooperação com a política de imigração do governo federal) em todo o país, em um esforço para apreender migrantes indocumentados. A expansão do muro da fronteira, cavalo de batalha de Trump, começou no Monumento Nacional Organ Pipe destruindo cemitérios e locais sagrados dos Tohono O'odham (uma tribo indígena cuja terra abrange a fronteira EUA-México) e removendo os cactus saguaro, espécie ambientalmente protegida, usados pelos Tohono O'odham em cerimônias e como alimento (Romero, 2020).

A criminalização de imigrantes por Trump tem um impacto aterrorizante sobre os alunos nas escolas (Gándara, 2020). "Existem muitas histórias de crianças com medo de frequentar a escola por receio de que seus pais não estejam mais em casa quando voltarem e temerosas de dormir à noite, esperando pela batida dos agentes de imigração e de execução" (Gándara, 2020, p. 44). Muitos observadores da região consideram essa militarização da fronteira e a criminalização de imigrantes um fator que contribui para as novas tendências de migração reversa que observamos agora no México (Passel; Cohn; Gonzalez-Barrera, 2012).

Um estudo recente com cinco mil educadores, conduzido pelo Projeto de Direitos Civis da Universidade da Califórnia em Los Angeles - UCLA (Gándara, 2020), revelou a sombria realidade das questões relativas à escolarização entre os jovens imigrantes. Dois terços dos professores relataram que, como consequência do regime de repressão, seus alunos imigrantes apresentavam um declínio no desempenho acadêmico. De acordo com um entrevistado: "Eles não estão pensando na escola ou no teste da próxima semana, ou no que está sendo ensinado em sala de aula hoje. Eles estão pensando em suas famílias e se ainda serão uma família; se a família não será atingida" (Gándara, 2020, p. 44).

\section{Um histórico de recomendações de pesquisa e de políticas}

Estima-se que existam cerca de dois milhões de pessoas vivendo na fronteira entre EUA e México, entretanto pouco se sabe sobre as formas de melhor agenciar professores e mantê-los nes- 
sas comunidades fronteiriças, geralmente rurais, cheias de desafios (Cline; Necochea, 2006). As pontuações dos testes dos alunos nas escolas de fronteira no Texas, Novo México e Arizona são sistematicamente inferiores às pontuações no restante do estado (McRobbie; Villegas, 2004). Há consciência de que os desafios enfrentados nas escolas de fronteira são peculiares e de que os professores não estão adequadamente preparados para educar esses alunos (López, 2017).

Pesquisas nos últimos 20 anos têm recomendado políticas para a melhoraria da educação dos estudantes da fronteira de forma consistente. Um estudo de 2004 (McRobbie; Villegas, 2004) realizado pelo WestEd, um centro de pesquisa educacional dos EUA, delineou os desafios educacionais transfronteiriços, indicou práticas promissoras em andamento naquele momento, como o programa de intercâmbio de professores, e recomendou o estabelecimento de uma Zona de Empreendedorismo Educacional ao longo da fronteira. Essa recomendação destaca a dimensão transnacional da educação na fronteira. Eles argumentam que, apesar de haver sistemas educacionais separados nos EUA e no México, a natureza entrelaçada da vida econômica e comunitária em cidades gêmeas fronteiriças exige colaboração internacional em projetos de educação.

O corpo de trabalho produzido pela equipe de pesquisa binacional de Victor Zuñiga, da Universidade de Monterrey, e Edmund Hamann, da Universidade de Nebraska, concentra-se nos fenômenos estudantis transfronteiriços emergentes que eles acompanham há mais de 10 anos. Estes pesquisadores cunharam um termo para se referir aos estudantes transnacionais, chamados de "sojourner students", ou seja, estudantes com residência temporária (Zuñiga; Hamann, 2009) ${ }^{2}$. Eles não veem esses estudantes apenas em termos de seus desafios, mas veem também as contribuições que tais alunos trazem para a escola. Eles concebem esses discentes como "uma vanguarda transformacional multinacional, bilíngue, bicultural e cosmopolita", mas para que esse potencial seja aproveitado, será necessário repensar a formação docente, os currículos e outros objetivos da política educacional (Jensen; Sawyer, 2013, p.186).

$\mathrm{O}$ mais recente trabalho etnográfico da equipe, nos estados mexicanos de Zacatecas, Puebla, Nuevo Leon e Jalisco destaca os

2 Sojourner, em inglês, significa peregrino, viajante, diarista, estrangeiro ou hóspede. (N.T.) 
desafios que os estudantes mexicano-americanos enfrentam ao retornar às escolas mexicanas, mais familiares para eles. Descobriu-se que os docentes mexicanos muitas vezes desconheciam a presença de estudantes transnacionais em suas salas de aula, sabiam pouco sobre seus históricos, tendiam a estar mais cientes de suas carências do que de suas contribuições e potencialidades, e sustentavam crenças comparativas sobre os dois sistemas que posicionavam favoravelmente as práticas mexicanas que eles conheciam melhor. Por outro lado, muitos desses professores também indicavam a necessidade de se saber mais sobre estudantes transnacionais e manifestavam o desejo de ajudar (Zuñiga; Hamann, 2009). Nesses estudos, os autores recomendam o desenvolvimento de um currículo binacional e intercâmbios docentes interfronteiras. Do mesmo modo, eles chamam a atenção para uma maior compreensão entre os professores a respeito dos fundos de conhecimento que os alunos trazem consigo. Além disso, citam trabalhos que reforçam a necessidade de um currículo multinacional e postulam uma coordenação binacional das políticas e práticas educacionais (Zuñiga; Hamann, 2009, p. 268).

Em seu estudo comparativo de 2007 entre escolas de Sonora e do Arizona, a pesquisadora Griego-Jones da Universidade do Arizona tomou como base para suas recomendações os achados do trabalho de campo realizado nas escolas de Sonora e as teorias de aprendizagem de Dewey (1938), Arends (2007) e Vygotsky (1978). Esses teóricos argumentam que o aprendizado do novo deve estar conectado ao conhecimento prévio que os alunos possuem e que esse conhecimento se estende para além do conteúdo específico, incluindo experiências de vida mais amplas. A partir dessa perspectiva, é vital que os docentes conheçam as experiências de vida dos alunos para sustentar e encorajar o processo de aprendizagem. Em razão desse quadro teórico, compartilhado por Hamann e Zuñiga, Griego-Jones recomenda que os professores de ambos os lados da fronteira tenham uma compreensão mais consistente da escolaridade em cada país. Ela recomenda o intercâmbio de professores e a inclusão de práticas educacionais binacionais nos programas de formação docente (Griego-Jones, 2010).

Em 2010, o Projeto de Direitos Civis da UCLA sediou, na Cidade do México, a conferência "Os Estudantes que Compartilhamos", que reuniu mais de 300 acadêmicos para tratar das necessidades dessa população estudantil transnacional emergente. Os artigos da 
conferência foram reunidos na publicação Regarding Education (Jensen; Sawyer, 2013). Essa coletânea de artigos elenca as principais questões dessa população e recomenda um enfoque binacional necessário para dar suporte a esse alunado, destacando a importância dos fundos de conhecimento que as crianças de origem mexicana trazem para a sala de aula. As recomendações incluídas nessa publicação destacam a necessidade de um maior intercâmbio docente e as habilidades dos professores para estabelecer um relacionamento autêntico com os alunos de origem mexicana, independentemente de que lado da fronteira a escola esteja. Além disso, foi indicado o uso da base de pesquisa que existe atualmente para implementar mudanças de longo prazo na política educacional na fronteira.

Os resultados dessa pesquisa acadêmica tiveram pouca possibilidade de aplicação devido às restrições políticas que orientam a política educacional. Por exemplo, o Memorando de Entendimento sobre Educação EUA-México não é oficialmente renovado desde 2004. Além disso, a agenda bilateral EUA-México tem sido dominada por questões de combate ao narcotráfico, segurança nas fronteiras e comércio. Qualquer aplicação significativa dos resultados da pesquisa para estudantes binacionais exigirá ação do governo no mais alto nível e, de fato, uma mudança na maneira como vemos os propósitos da educação escolar.

\section{Propósitos da escolarização}

Os pesquisadores discutem um desafio fundamental para as iniciativas educacionais binacionais: a base nacionalista da escolarização. $O$ fronteirólogo Anssi Paasi inclui as escolas como parte do aparato ideológico nacional de um país a moldar as narrativas identitárias (Paasi, 2011). Para contemplar o objetivo nacionalizante da educação, as escolas também se dedicam a preparar os trabalhadores. Desde a publicação do seminal relatório "Uma nação em risco” pela Comissão Nacional de Excelência em Educação (National Commission on Excellence in Education, 1983), as escolas dos EUA passaram a ser vistas como instrumentos institucionais das economias modernas encarregadas de fornecer mão-de-obra que possa ser produtiva em mercados de trabalho emergentes (Spener, 1988).

Nos EUA e no México, elas são vistas como a principal instituição encarregada de formar cidadãos bons e leais: 
Um dos desafios do transnacionalismo surge do fato de as escolas na maioria dos países terem sido institucionalmente concebidas para servir interesses, metas e visões nacionais / locais. Os currículos escolares - as línguas, valores, tradições, narrativas e símbolos - são territorializados desde o século XIX ou início do século XX. Em essência, eles são territorializados desde que a escolarização se tornou uma expectativa popular. (Zuñiga; Hamann, 2009, p. 5).

Um livro de 2003 sobre educação binacional na fronteira de El Paso / Juarez (Rippberge; Staudt, 2003) descreve o caráter nacionalista da educação nas escolas da fronteira. As autoras afirmam que os alunos que têm experiências educacionais transfronteiriças enfrentam mais desafios, dada a natureza nacionalista do currículo escolar:

O Texas oferece suas próprias versões estaduais de valores, narrativas históricas e bandeiras, enquanto o México tem um currículo nacionalista que vem da capital nacional. Isso pode ser desconcertante para crianças imigrantes expostas à educação cívica em seus países de origem e posteriormente em seu novo país. Elas aprenderam que é apropriado mostrar respeito e amor inquestionáveis pelo governo, pela história e por quem tem autoridade e, mais tarde, nos EUA, devem aprender novos valores sociais individualistas (Rippberge; Staudt, 2003, p. 140).

Em seu trabalho, elas sugerem uma regionalização do currículo para formar cidadãos binacionais. Isso implica limitar os sagrados rituais e mitos patrióticos sobre o nacionalismo (Rippberge; Staudt, 2003, p. 146).

\section{Formação binacional de professores: particularidades do lugar}

Nossa capacidade de usar a pesquisa educacional para moldar a prática é sempre limitada pela ecologia econômica, política e social na qual as políticas educacionais são forjadas. $O$ trabalho descrito acima fornece algumas orientações novas para o desen- 
volvimento da formação docente para professores de escolas de fronteira. Os educadores que vivem e trabalham na fronteira sabem que os problemas de escolarização que enfrentam são únicos e exigem um tipo de preparação diferente para a docência (Cline; Reyes; Necochea, 2009). As recomendações provenientes de pesquisas nos últimos 20 anos sugerem um caminho a seguir para esse novo tipo de formação docente.

A noção de particularidade do "lugar" ao longo da fronteira (Paasi, 2011) questiona a ideologia atual na formação de professores, a qual sugere que "boas práticas" são "boas práticas”, quer se trate de escolas urbanas, suburbanas ou rurais. As aulas de metodologia de ensino geralmente destacam técnicas para ensinar inglês como língua estrangeira, mas não consideram especificamente os alunos transfronteiriços ou com residência temporária. Os recentes programas on-line de capacitação docente são, por definição, não-específicos ao lugar.

Como deveria ser, então, a formação dos professores para as escolas de fronteira? Um programa binacional de formação docente irá garantir que os novos professores tenham experiências práticas em escolas nos dois lados da fronteira. Essas experiências ajudariam a familiarizar os professores em formação com os costumes e práticas provavelmente comuns a muitos de seus alunos. Esse tipo de intercâmbio pode começar informalmente com visitas de campo frequentes a diversas escolas. Entretanto, ao longo de um programa de formação docente para a fronteira, seria necessário incluir uma experiência de imersão mais longa.

Um programa binacional de formação docente deverá fornecer um treinamento básico de idiomas para que os docentes tenham um certo nível de conforto tanto com o espanhol quanto com o inglês. Isso irá garantir que as escolas de fronteira sejam lugares acolhedores para todos os alunos e que os professores americanos nessas escolas possam se comunicar melhor com seus alunos e familiares.

Um programa binacional de formação de professores precisará incluir trabalho contínuo nas áreas de história cultural das fronteiras. Em nosso contexto, isso significaria construir entre os candidatos à docência uma compreensão sistemática das diversas culturas que convivem ao longo da fronteira Arizona-México, incluindo a rural, a mineradora, a de Sonora e a dos nativos america- 
nos. Isso iria além de qualquer sala de aula multicultural existente, concentrando-se diretamente na fronteira. Além disso, questões da vida na fronteira seriam integradas a todo o curso, não apenas a um tópico autônomo sobre cultura. $\mathrm{O}$ arcabouço conceitual com que os professores da fronteira precisam operar deve incluir as questões políticas, ambientais e econômicas que os habitantes da fronteira enfrentam diariamente.

Um programa binacional de formação de professores necessitará incorporar um enfoque binacional ao currículo. A natureza nacionalista do currículo escolar, seja nos EUA ou no México, é projetada para criar cidadãos. Dada a mobilidade e a identidade binacional dos estudantes nas escolas de fronteira, faz sentido ir além dessa maneira tradicional de olhar os currículos ofertados nas escolas. Em seu estudo de Nogales, Arizona / Sonora, Goldberg (2001) analisa o desenvolvimento da identidade dos alunos nas escolas de fronteira e conclui: "Talvez devêssemos contrastar um fronteiriço com alguém que vive no interior de cada país, em vez de aplicar um modelo de base nacional a pessoas cujas vidas transcendem as fronteiras nacionais.” (Goldberg, 2001, p. 85).

Todos haverão de reconhecer que esse novo enfoque para a formação docente representa uma mudança radical em relação aos programas já existentes, que normalmente assumem uma perspectiva nacionalista. Porém, é necessário mudar tal enfoque para que as escolas de fronteira preparem melhor os alunos para a continuidade de suas vidas binacionais. Esse enfoque aumentaria a eficiência dos professores de fronteira, oferecendo a eles um currículo binacional enriquecido e as experiências transculturais necessárias para que entendam melhor seus alunos e os preparem para a vida adulta.

E se ao invés de supormos um modelo de déficit para os alunos (Gonzalez; Moll; Amanti, 2005; Matthews; Lopez, 2019), nós considerássemos os estudantes fronteiriços uma nova forma de "estudantes internacionais'? Tais estudantes, florescentes cidadãos bilíngues e biculturais, podem estar na vanguarda de um novo tipo discente cujas necessidades educacionais divergem significativamente das instituições que os atendem. A incompatibilidade entre os programas educacionais nacionalistas e essa nova identidade internacional emergente é ainda mais problemática quando consideramos o papel das escolas no desenvolvimento da identidade (Verhoeven; 
Poorthuis; Volman, 2019). Além disso, o robusto construto teórico de fundos de conhecimento sugere que o exercício da docência não poderá atender adequadamente os alunos sem que se conheça bem quem eles efetivamente são. Esse construto defende experiências binacionais mais enriquecidas para os professores (Gonzalez; Moll; Amanti, 2005). Pesquisadores educacionais descrevem essa nova realidade educacional para estudantes mexicanos-americanos desde os anos 1990, não seria hora de ouvi-los e de agir?

\section{Referências}

ARENDS, R.I. Learning to Teach. 7th ed. New York: McGraw-Hill, 2007.

ANZALDÚA, G. Borderlands/La Frontera. San Francisco: Aunt Lute Books, 2011.

ASSOCIATED PRESS. Arizona judge declares ban on ethnic studies unconstitutional. 2017. Disponível em: www.nbcnews.com/news/ latino/arizona-judge-declares-ban-ethnic-studies-unconstitutional-n833126

CLINE, Z.; REYES, M. L.; NECOCHEA, J. Introduction to the Special Issue: Educational Lives on the Border. Journal of Latinos And Education, v. 4, n. 3, p. 149-152, 2009.

CLINE, Z.; NECOCHEA, J. Teacher Dispositions for Effective Education in the Borderlands. The Educational Forum, 2006, v. 70, n. 3, p. 268-282,. DOI: doi.org/10.1080/00131720608984902

DEWEY, J. Experience and Education. New York: Touchstone, 1938. DUNN, Alyssa Hadley. Teachers Without Borders. New York: Teachers College Press, 2013.

ELENES, C. Transforming Borders. Lexington: Maryland, US., 2011.

FLYNN, M. Arizona migrant detention facilities, where some sleep in bathroom stalls, are unfit for humans, judge rules. The Washington Post, fev. 2020, Disponível em: https://www.washingtonpost. com/nation/2020/02/20/arizona-detention-facilities-unconstitutional/

GÁNDARA, P. The students we share: falling through the cracks on both sides of the US-Mexico border. Ethnic and Racial Studies,43:1,38-59, 2020. DOI: 10.1080/01419870.1667514 
GOLDBERG, A. Transnationalism and Borderlands: Concepts of Space on the US-Mexico Border and Beyond. Estudios Fronterizos, v.2, n. 4, p. 49-92, 2001.

GONZALEZ, N.; MOLL, L.; AMANTI, C. Funds of Knowledge: Theorizing Practices in Households, Communities and Classrooms. New York: Routledge Press, 2005.

GRIEGO-JONES, T. Transnational Classroom Research: Comparing Classrooms Along the U.S.-Mexican Border (Arizona-Sonora). ICERI20 Proceedings, p. 6141-6147, 2010. Disponível em: https:// library.iated.org/view/GRIEGOJONES2010TRA

JENSEN, B.; SAWYER, A. (Eds.). Regarding Educacion. New York: Teachers College Press, 2013.

LÓPEZ, F. Altering the trajectory of the self-fulfilling prophesy: Asset-based pedagogy and classroom dynamics. Journal of Teacher Education, v. 68, p. 193-212, 2017.

MATTHEWS, J. Sharif; LÓPEZ, Francesca. Speaking their language: The role of cultural content integration and heritage language for academic achievement among Latino children. Contemporary Educational Psychology, v. 57, 2019, p. 72-86.

McROBBIE, J.; VILLEGAS, M. La Frontera: Challenges and Opportunities for Improving Education Along the U.S.-Mexico border. WestEd Research Center, 2004. Disponível em: https://www.wested.org/online_pubs/frnt-04-01.pdf

NATIONAL COMMISSION ON EXCELLENCE IN EDUCATION. A Nation at Risk:The imperative for educational reform. U.S.: United States Department of Education, 1983.

OROZCO, R. Education across the U.S. Mexico Border. Presentation delivered at AZ-TESOL Conference, Tucson, AZ, 2008.

PAASI, A. A "Border Theory": an unattainable dream or a realistic aim for border scholars. In: WASTL-WALTER, Doris. (Ed.) The Ashgate Research Companion to Border Studies. Abingdon: Routledge, 2011. Disponível em: https://doi-org.ezproxy3.library.arizona.edu/ 10.1080/08865655.2011.675718

PASSEL, J.; COHN, D.; GONZALEZ-BARRERA, A. Net Migration from Mexico Falls to Zero-and Perhaps Less. Pew Research Hispanic Center: Washington, DC, 2012. Disponível em: https://www. 
pewresearch.org/hispanic/2012/04/23/net-migration-from-mexico-falls-to-zero-and-perhaps-less/

RIPPBERGER, S.; STAUDT, K. Pledging Allegiance: Learning Nationalism at the El Paso-Juarez Border. New York: Routledge Falmer, 2003.

ROMERO, S. Tribal nation condemns desecration to build border wall. The New York Times, fev. 2020. Disponível em: https://www. nytimes.com/2020/02/26/us/border-wall-cactuses-arizona.html?searchResultPosition $=1$

SPENER, D. Transitional Bilingual Education and the Socialization of Immigrants. Harvard Educational Review, v. 58, n. 2, p. 133-153, 1988. VALDES, G. Con Respeto: Bridging the Distances Between Culturally Diverse Families and Schools. New York: Teachers College Press, 1996.

VERHOEVEN, M.; POORTHUIS, A.M.G.; VOLMAN, M. The Role of School in Adolescents' Identity Development. A Literature Review. Educational Psychology Review, v. 31, p. 35-63, 2019. Disponível em: doi.org/10.1007/s10648-018-9457-3

VYGOTSKY, L. Mind in Society: The Development of Higher Psychological Processes. Boston: Harvard University Press, 1978.

ZUÑIGA, V. HAMANN, E. Sojourners in Mexico With U.S. School Experience: A New Taxonomy for Transnational Students. University of Nebraska-Lincoln: 2009. Disponível em: http://digitalcommons.unl.edu/teachlearnfacpub/91 